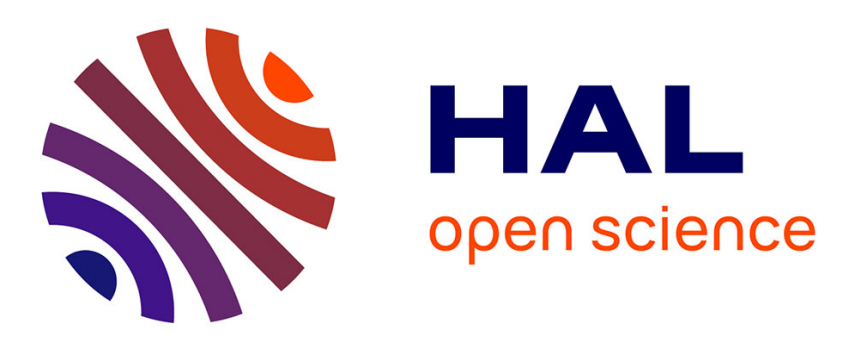

\title{
Magnetic vibrational Raman scattering of KI doped with $\mathbf{F}$ centres
}

\author{
M. Billardon, M.F. Russel, J.P. Buisson, S. Lefrant
}

\section{To cite this version:}

M. Billardon, M.F. Russel, J.P. Buisson, S. Lefrant. Magnetic vibrational Raman scattering of KI doped with F centres. Journal de Physique Lettres, 1976, 37 (10), pp.251-253. 10.1051/jphyslet:019760037010025100 . jpa-00231286

\section{HAL Id: jpa-00231286 https://hal.science/jpa-00231286}

Submitted on 1 Jan 1976

HAL is a multi-disciplinary open access archive for the deposit and dissemination of scientific research documents, whether they are published or not. The documents may come from teaching and research institutions in France or abroad, or from public or private research centers.
L'archive ouverte pluridisciplinaire HAL, est destinée au dépôt et à la diffusion de documents scientifiques de niveau recherche, publiés ou non, émanant des établissements d'enseignement et de recherche français ou étrangers, des laboratoires publics ou privés. 


\title{
MAGNETIC VIBRATIONAL RAMAN SCATTERING OF KI DOPED WITH F CENTRES
}

\author{
M. BILLARDON $\left({ }^{*}\right)$, M. F. RUSSEL $\left({ }^{*}\right)$
}

Laboratoire d'Optique Physique, ESPCI, 10, rue Vauquelin, 75231 Paris, France

and J. P. BUISSON $\left({ }^{* *}\right)$, S. LEFRANT $\left({ }^{* *}\right)$

Laboratoire de Physique Cristalline, Université de Paris-Sud, Bât. 490, 91405 Orsay, France

(Reçu le 10 juin 1976, accepté le 15 juillet 1976)

\begin{abstract}
Résumé. - Nous avons étudié la diffusion Raman, sous champ magnétique, de KI dopé avec des centres $F$. L'interprétation des spectres exige la prise en compte du couplage spin-orbite de l'état excité ${ }^{2} \mathbf{P}$ du centre $\mathbf{F}$. Les principales caractéristiques de ces spectres sont au moins qualitativement en accord avec le modèle simple de l'approximation quasi résonante.
\end{abstract}

Abstract. - We have studied the Raman scattering under magnetic field by F centres in $\mathrm{KI}$. The spin orbit coupling of the ${ }^{2} \mathrm{P}$ excited state must be taken into account in order to explain the observed spectra. The simple model of the quasi-resonant approximation provides a reasonably exact description of the observed features.

Experimental studies of Raman scattering by $\mathrm{KI}$ doped with $F$ centres have been previously published $[1,2]$. We recall that in the off resonance approximation the active modes are of $\Gamma_{1}^{+}, \Gamma_{3}^{+}$and $\Gamma_{5}^{+}$symmetry. At $10 \mathrm{~K}$ the spectra show a very intense and sharp line at $96 \mathrm{~cm}^{-1}$, which has been attributed to a $\Gamma_{1}^{+}$resonant optical mode. Indeed the calculation predicts a strong resonant $\Gamma_{1}^{+}$mode, but is unable to account for the $96 \mathrm{~cm}^{-1}$ line which appears in the $\Gamma_{3}^{+}$and $\Gamma_{5}^{+}$spectra. However we have recently shown that the spin-orbit interaction in the excited state could explain rather satisfactorily this feature [2].

In order to check this hypothesis we have performed Raman scattering experiments in a magnetic field, which turns out to be the relevant perturbation for this purpose.

The KI crystal doped with $\mathrm{F}$ centres (the maximum of the absorption band lies at $660 \mathrm{~nm}$ at $10 \mathrm{~K}$ ) was excited with a dye laser which could be tuned between 590 and $625 \mathrm{~nm}$. The light power could be ranged between 60 and $300 \mathrm{~mW}$. A magnetic field of $4.5 \mathrm{~T}$ was provided by a superconducting manet and the experiments were performed at $1.7 \mathrm{~K}$. A sketch of the experimental arrangement is reported in the insert of figure 1 . The directions of the incident and scattered beams were parallel to the four-fold $O x$ and $O z$ axes

(*) Equipe de Recherches No 5 du C.N.R.S.

(**) Equipe de Recherches Associée au C.N.R.S. No 13.

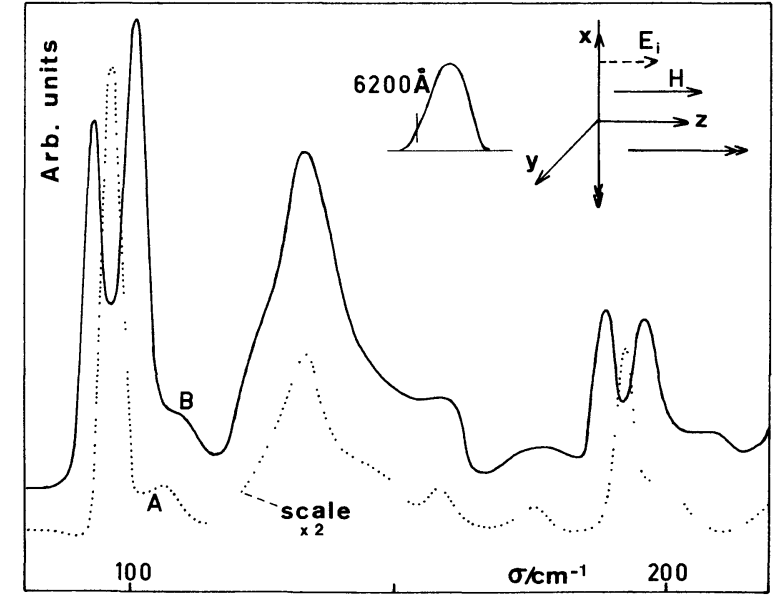

FIG. 1. - The Raman scattering of KI doped with F centres for the experimental arrangement sketched top right. $X, Y, Z$, are the four-fold axes of the crystal; the linear polarization of the incident light $\left(\mathbf{E}_{\mathrm{i}}\right)$, the magnetic field $(H)$ and the direction of the scattered beam were along the $O z$ axis. In this experiment no analysis of the polarization of the scattered light was performed. Laser wavelenght, $620 \mathrm{~nm}$; laser power, $140 \mathrm{~mW}$; slit-width, $3 \mathrm{~cm}^{-1}$. Curve A : Raman scattering without magnetic field. Curve B : Raman scattering under $4.5 \mathrm{~T}$ magnetic field.

respectively. The magnetic field was along the $O z$ axis as was the linear polarization of the incident light.

If the spin orbit coupling in the ${ }^{2} \mathrm{P}$ excited state was neglected, this configuration would only lead to the determination of $\Gamma_{5}^{+}$modes. Actually the 
Raman spectrum observed without magnetic field (Fig. 1 curve A) exhibits the $96 \mathrm{~cm}^{-1}$ resonant mode and its first overtone at $193 \mathrm{~cm}^{-1}$. The broad band at $130 \mathrm{~cm}^{-1}$ has been partially attributed to the optical modes of $\Gamma_{5}^{+}$symmetry. When the magnetic field is applied an apparent feature of the experiment turns out to be the splitting of both $96 \mathrm{~cm}^{-1}$ mode and its first overtone (Fig. 1 curve B).

This observed feature may be understood in terms of the scheme reported in figure 2. On this figure the ${ }^{2} \mathrm{~S}$ ground state of the $\mathrm{F}$ centre is sketched. The application of the magnetic field splits the 0 and 1 vibronic levels into two sub-levels possessing the magnetic quantum numbers $\pm \frac{1}{2}$. Then the Raman spectrum should exhibit three lines. Two of them correspond to transitions involving a spin flip $\left(v_{+}\right.$and $v_{-}$) and are separated by $2 g \beta H$. The other one which does not involve any spin flip would lie at the same frequency as the original one.
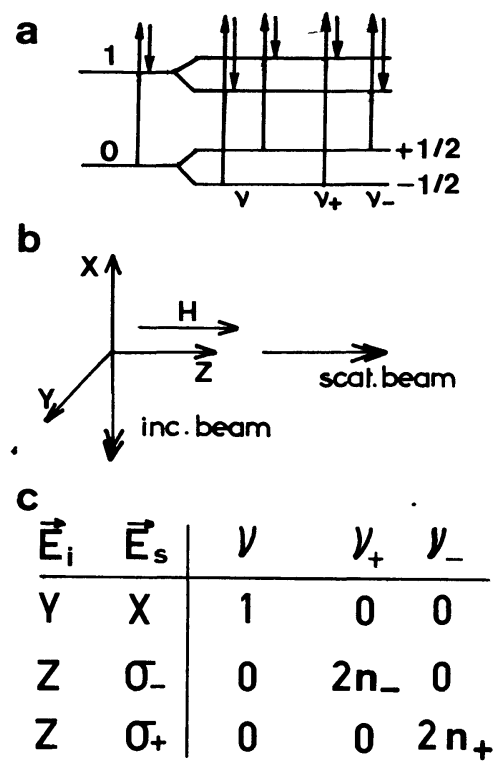

FIG. 2a. - Scheme of the Raman frequencies under magnetic field for a ${ }^{2} \mathrm{~S}$ ground state. Only the two first vibronic levels $(0,1)$ with their magnetic sub-levels $\left( \pm \frac{1}{2}\right)$ are represented on this figure. $v$ is the Raman frequency without any magnetic field, $v_{ \pm}$are the Raman frequency involving a spin flip. $b$ ) Experimental configuration used for the study of the magnetic Raman scattering due to a $\Gamma_{1}^{+}$ phonon. $X, Y, Z$ are the four-fold axes of the crystal. $c$ ) Relative intensities of the three Raman lines for a $\Gamma_{1}^{+}$phonon and for the configuration of the figure $2 b . \mathbf{E}_{\mathrm{i}}$ is the linear polarization of the incident beam ; $\mathbf{E}_{\mathrm{s}}$ is the linear or circular polarization vector of the scattering beam. $n_{ \pm}$are the populations of the magnetic sublevels of the 0 vibronic ground state.

In order to determine the selection rules corresponding to the configuration of the figure $2 b$, we have taken into account the spin orbit and the Zeeman interactions. For this purpose we have used the Raman theory developped by Henry [3] and Buchenauer [4] in the quasi-resonant approximation. Bedises the classical terms only due to electron-lattice coupling, we then obtain second order terms whose magnitude is proportional to $\left(C_{\mathrm{i}} C_{\mathrm{so}}\right)^{2} . C_{\mathrm{i}}$ and $C_{\mathrm{so}}$ are the coupling constants for electron-lattice and spin-orbit interactions in the excited state ${ }^{2} \mathrm{P}$. For a $\Gamma_{1}^{+}$mode the relative intensities of these latter terms are indicated in figure $2 c$. The same calculation can be performed in the case of scattering by phonons of $\Gamma_{3}^{+}$and $\Gamma_{5}^{+}$symmetry. The intensities of the $v_{+}$and $v_{-}$lines are still proportional to $C_{\mathrm{so}}^{2}$ but the selection rules depend upon the symmetry of the mode involved and are different from the $\Gamma_{1}^{+}$case.

In particular the broadening of the $130 \mathrm{~cm}^{-1}$ line can be explained by transitions due to the spin flip. In this case more detailed results could be obtained with the technique of Raman circular intensity differential as reported by Barron [5].

We have then studied the $96 \mathrm{~cm}^{-1}$ line according to the state of polarization of the scattered light as is shown in figure 2, and found the following :

1) If $\left(\mathbf{E}_{\mathrm{i}}, \mathbf{E}_{\mathrm{s}}\right) \equiv(\mathbf{Y}, \mathbf{X})$, no modification of the line appears under magnetic field, in agreement with the selection rules.

2) If $\left(\mathbf{E}_{\mathrm{i}}, \mathbf{E}_{s}\right) \equiv\left(\mathbf{Z}, \sigma_{ \pm}\right)$, the results are indicated figure 3. According to the selection rules for a $\Gamma_{1}^{+}$ mode, the central line $(v)$ disappears and both $v_{+}$ and $v_{-}$lines are maintained and separated by $7.9 \mathrm{~cm}^{-1}$ in good agreement with the theoretical value $2 \mathrm{~g} \beta H=8.4 \mathrm{~cm}^{-1}$. On the other hand, at $1.7 \mathrm{~K}$ the two spectra $\sigma_{+}$and $\sigma_{-}$are observed with nearly equal intensities. The same phenomenon occurs using a $600 \mathrm{~nm}$ laser line, i.e. out of the $\mathrm{F}$ absorption band, but in the $\mathrm{K}$ band. As is obvious from figure $2 c$, the ground state sub-level populations are not governed by the classical Boltzman law. Such a deviation from the Boltzman equilibrium may be attributed to the long spin-lattice relaxation time and to the spin memory loss during the pumping cycle.

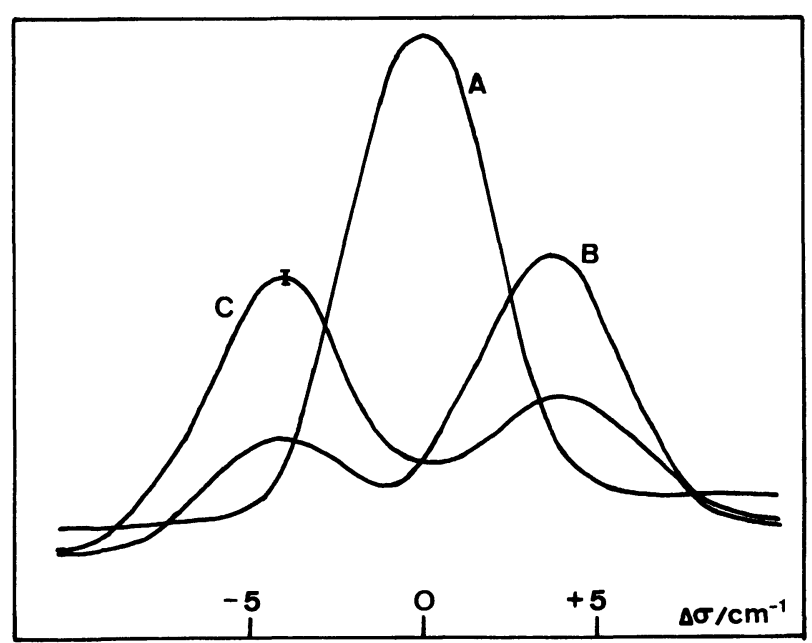

FIG. 3. - Raman scattering of the $96 \mathrm{~cm}^{-1}$ resonant mode for the $\left(\mathbf{E}_{\mathrm{i}}, \mathbf{E}_{\mathrm{s}}\right) \equiv\left(\mathbf{Z}, \sigma_{ \pm}\right)$configuration of the figure 2 . Laser wavelength, $620 \mathrm{~nm}$; laser power, $140 \mathrm{~mW}$; slit width, $3 \mathrm{~cm}^{-1}$; magnetic field, $4.5 \mathrm{~T}$. Curve $\mathrm{A}$ : Raman scattering without magnetic field and for a $\sigma_{+}$or $\sigma_{-}$scattered polarization. Curve B and C : Raman scattering under 4.5 $\mathrm{T}$ magnetic field for $\sigma_{-}$and $\sigma_{+}$scattered polarizations respectively. 
Moreover as can be seen in figure 3 a rather strong depolarization ( $30 \%$ ) exists for both $v_{+}$and $v_{-}$lines. The origin of these effects is not clear, but several explanations can be proposed : for example one can invoke the internal stresses, the hot fluorescence process, or the failure of the off-resonance approximation used in our calculation.

In conclusion, as previously predicted by Buchenauer [4] and Mulazzi [6] the classical selection rules are not strictly observed when the spin-orbit interaction in the excited state of the $F$ centre is taken into account. Therefore, Raman spectra under magnetic field allow one to test the breaking of selection rules. Such experiments would be interesting in particular for the study of broad bands generally observed in Raman spectra of crystals doped with impurities or defects.

\section{References}

[1] Buisson, J. P. and Taurel, L., Phys. Status Solidi (b) 63 (1974) K 81.

[2] Buisson, J. P., Sadoc, A., Taurel, L. and Billardon, M., Light scattering in solids Sd. by Balkanski M., Leite R.C.C., Porto S.P.S. (Paris Flammarion) 1975.

[3] Henry, C. H., Phys. Rev. 152 (1966) 699.

[4] Buchenauer, C. J., Thesis (1971).

[5] BARRon, L. D., Nature 257 (1975) 372.

[6] Mulazzi, E. and Terzi, N., Solid State Commun. 18 (1976) 721. 